\title{
Welfare gains from urbanizing landscapes in Great Barrier Reef catchments? A spatial environmental-economic modelling approach
}

\author{
P. C. Roebeling ${ }^{1}$, C. S. Fletcher ${ }^{1}$, D. W. Hilbert ${ }^{1} \&$ J. Udo ${ }^{2}$ \\ ${ }^{I}$ Tropical Landscapes Program, CSIRO Sustainable Ecosystems, \\ Australia \\ ${ }^{2}$ Department of Economics, University of Tilburg, The Netherlands
}

\begin{abstract}
The Reef Water Quality Protection Plan aims at 'halting and reversing the decline in water quality' entering the Great Barrier Reef (GBR) by 2015. Population growth rates in GBR catchments are, however, amongst the largest in Australia and expected to lead to substantial changes in land use, a subsequent decline in water quality and degradation of the GBR ecosystem. This paper explores welfare gains that can be obtained from population growth in a linked terrestrial and marine ecosystem, using a deterministic optimal control approach in which we equate terrestrial benefits from population induced residential development patterns and, subsequent, marine costs from water pollution associated with these development patterns. Patterns of land use development are thereby explored using a classic urban economic model with environmental amenities, while associated water quality impacts are assessed using a water quality model. For a case study catchment in the Wet Tropics of Australia, results show that the welfare maximizing population size depends to a large extent on whether downstream costs from water pollution are taken into account. Ignoring downstream costs from water pollution leads to welfare maximizing populations that are multiple times the current catchment population. Accounting for these downstream costs, however, leads to welfare maximizing populations that are only a fraction larger than the current catchment population.

Keywords: regional planning, urbanizing landscapes, watershed management, optimal control, spatially-explicit models.
\end{abstract}




\section{Introduction}

The Reef Water Quality Protection Plan (RWQPP) is aimed at 'halting and reversing the decline in water quality' entering the Great Barrier Reef (GBR) by 2015 [16]. Population growth rates in the GBR catchments are, however, amongst the highest in Australia while associated residential developments are expected to lead to a decline in water quality, degradation of the GBR ecosystem and subsequent losses in marine economic values [2, 13, 18, 23].

Previous studies relating terrestrial economic land use activities, associated water pollution and, subsequent, changes in marine economic values $[5,10,13$, $15,19]$, particularly focused on agricultural land use and land management for water quality improvement, though ignored urbanization of these agricultural landscapes. Consequently, they potentially underestimated returns from land use conversion and overestimated potentials for water quality improvement.

The objective of this paper is to explore welfare gains that can be obtained from population growth and associated residential development, in a linked terrestrial and marine ecosystem. To this end we develop a deterministic optimal control approach in which we equate terrestrial benefits from population induced residential development patterns and, subsequent, marine costs from water pollution associated with these residential development patterns. Patterns of land use development are explored using a classic urban economic model with environmental amenities [20,21], while associated water quality impacts are assessed using the water quality model SedNet/ANNEX [1, 7, 22]. A numerical application of the model is provided for the Douglas Shire catchment in the Wet Tropics of Queensland, Australia.

In the next section, a deterministic optimal control model of urbanization in a linked terrestrial and marine ecosystem is developed and derived analytically. In Section 3 we estimate, for the Douglas Shire case study, parameter values for terrestrial benefits from urbanization, associated water pollution impacts from urbanization, and, in turn, marine costs from water pollution. Based on these parameter estimates and using the deterministic model of urbanization, we determine, in Section 4, welfare maximizing catchment populations in the Douglas Shire catchment. Finally, Section 5 presents and discusses the most important findings of this study.

\section{A model of urbanization in a linked terrestrial and marine ecosystem}

Previous studies that relate terrestrial based economic land use activities to water pollution, indicators of reef health and, subsequent, changes in marine based economic values $[5,10,13,15,19]$, particularly focused on agricultural land use and land management for water quality improvement though ignored urbanization of these agricultural landscapes. Urbanizing landscapes have, however, proven to impact terrestrial based economic activities and values, water quality and, in turn, marine based economic values [18, 23]. In this section we 
develop a deterministic optimal control approach to explore welfare gains that can be obtained from urbanization in a linked terrestrial and marine ecosystem.

To this end we adjust the model developed by [13], such that $B_{t e r}\left(Q_{t}\right)$ denotes total terrestrial benefits from agricultural and residential land uses in the GBR catchment that are a function of catchment population $Q_{t}$ (control variable), $B_{\text {mar }}\left(P_{t}\right)$ denotes total marine benefits from economic values of the GBR that are a function of the level of marine water pollution $P_{t}$ (stock variable), and $\dot{P}_{t}$ denotes the change in the level of marine water pollution as function of catchment population $Q_{t}$ and the level of marine water pollution $P_{t}$. The annual flow of net benefits $\pi\left(P_{t}, Q_{t}\right)$ is given by the sum of terrestrial and marine benefits, so that the optimal control welfare $(W)$ maximizing problem becomes

$$
\underset{R_{t}}{\operatorname{Max}} W=\int_{0}^{\infty}\left[\pi\left(P_{t}, Q_{t}\right)\right] e^{-r t} d t
$$

subject to $\quad \dot{P}_{t}=f\left(P_{t}, Q_{t}\right)$

(equation of motion for $P_{t}$ )

and

$$
\begin{aligned}
& P_{0}>0 \text { and } Q_{0}>0 \\
& P_{t} \geq 0 \text { and } Q_{t} \geq 0
\end{aligned}
$$

(initial conditions)

where $r$ is the time discount rate, $f\left(P_{t}, Q_{t}\right)$ is the equation of motion for $P_{t}$, and where a dot over a variable denotes the derivative of that variable with respect to time $t$. The current value Hamiltonian, while omitting time notation, is given by

$$
H=\pi(P, Q)+\lambda(f(P, Q))
$$

where $\lambda$ is the costate variable representing the future marginal costs of water pollution. Assuming an interior solution and using the necessary conditions for an optimal solution, the steady state (i.e. $\dot{\lambda}=\dot{P}=0$ ) population $Q$ is given by

$$
\pi_{Q}=\frac{-\pi_{P} f_{Q}}{\left(r-f_{P}\right)}
$$

where $\pi_{Q}=d \pi / d Q, \pi_{P}=d \pi / d P, f_{Q}=d f / d Q$ and $f_{P}=d f / d P$. Eqn (3) states that the optimal choice $Q^{*}$ must be such that the current marginal benefits from catchment population $Q$ balance against the future marginal costs induced by this catchment population $Q$ via the change in the level of marine water pollution $P$.

Application of the above described model requires the specification (this section) and estimation (Section 3) of functional forms for $B_{t e r}\left(Q_{t}\right), \dot{P}_{t}$ and $B_{\operatorname{mar}}\left(P_{t}\right)$. We take terrestrial benefits $B_{t e r}\left(Q_{t}\right)$ to be increasing in the catchment population $Q_{t}$, while recognizing positive terrestrial benefits from agricultural land use in the absence of residential land use $\left(\alpha_{1}>0\right)$ and acknowledging 
decreasing marginal benefits from population growth $\left(\alpha_{2}>0\right.$ and $\left.\alpha_{3}<0\right)$. Terrestrial benefits can bow be given by the second order polynomial

$$
B_{t e r}\left(Q_{t}\right)=\alpha_{1}+\alpha_{2} Q_{t}+\alpha_{3} Q_{t}^{2}
$$

We take marine benefits $B_{\text {mar }}\left(P_{t}\right)$ to be linearly decreasing in the level of marine water pollution $P_{t}$, so that

$$
B_{\text {mar }}\left(P_{t}\right)=\beta_{1}+\beta_{2} P_{t}
$$

where $\beta_{1}$ denotes the marine benefits from economic use and non-use values of the GBR in the absence of water pollution $\left(\beta_{1}>0\right)$ and where $\beta_{2}$ denotes marginal water pollution costs $\left(\beta_{2}<0\right)$.

Net benefits $\pi\left(P_{t}, Q_{t}\right)$ are now given by the sum of terrestrial benefits $B_{\text {ter }}\left(P_{t}\right)$ and marine benefits $B_{\text {mar }}\left(P_{t}\right)$, so that

$$
\pi\left(P_{t}, Q_{t}\right)=\alpha_{1}+\alpha_{2} Q_{t}+\alpha_{3} Q_{t}^{2}+\beta_{1}+\beta_{2} P
$$

Finally, the equation of motion for marine water pollution $\left(\dot{P}_{t}\right)$ is determined by the rate of water pollution from terrestrial land uses $\left(g\left(Q_{t}\right)\right)$ net of the fraction of marine water pollution lost from the system $\left(\rho P_{t}\right)$, so that

$$
\dot{P}_{t}=g\left(Q_{t}\right)+\rho P_{t}
$$

with

$$
g\left(Q_{t}\right)=\gamma_{1}+\gamma_{2} Q_{t}+\gamma_{3} Q_{t}^{2}
$$

and where $-1<\rho<0$. The rate of water pollution from terrestrial land uses $\left(g\left(Q_{t}\right)\right)$ is taken to be increasing in the catchment population $Q_{t}$, while recognizing water pollution from non-residential land uses $\left(\gamma_{1}>0\right)$ and acknowledging increasing marginal rates of water pollution from population growth $\left(\gamma_{2}>0\right.$ and $\left.\gamma_{3}<0\right)$.

Substitution of the first order derivatives of $\pi\left(P_{t}, Q_{t}\right)$ and $f\left(P_{t}, Q_{t}\right)$ back into eqn (3) and solving for $Q_{t}$ now yields the steady state catchment population $Q^{*}$

$$
Q^{*}=\frac{-\alpha_{2}(r-\rho)-\beta_{2} \gamma_{2}}{2 \alpha_{3}(r-\rho)+2 \beta_{2} \gamma_{3}}
$$

Eqn (9) is decreasing in $\alpha_{3} \beta_{2}, \gamma_{2}, \gamma_{3}$ and $\rho$, and increasing in $\alpha_{2}$ and $r$.

\section{Case study for the Wet Tropics of Australia: Douglas Shire}

The above model is applied the Douglas Shire catchment in the Wet Tropics of Queensland, Australia. We estimate parameter values for terrestrial land use 
benefits $B_{t e r}\left(Q_{t}\right)$, terrestrial land use water pollution $g\left(Q_{t}\right)$ and marine benefits $B_{\text {mar }}\left(P_{t}\right)$ to determine, in Section 4, welfare maximizing populations $Q^{*}$ in the Douglas Shire catchment.

\subsection{Terrestrial benefits from agricultural and residential land uses}

Terrestrial benefits from agricultural and non-agricultural land uses $B_{t e r}\left(Q_{t}\right)$ are taken to be increasing in the catchment population, while recognizing positive terrestrial benefits from agricultural land use in the absence of residential land use and acknowledging decreasing marginal benefits from population growth (see eqn (4)). To explore land use patterns and corresponding terrestrial benefits for different catchment population scenarios, we develop a classic urban economic model with environmental amenities in Section 3.1.1 and apply the model to the Douglas Shire catchment in Section 3.1.2.

\subsubsection{Classic urban economic model with environmental amenities}

The classic urban economic model with environmental amenities, see for example [20,21], has it's foundations in the Alonso-Muth-Mills bid rent model $[11,12]$. The idea behind the model is that households optimize their residential location by trading off utility from environmental amenities, residential space and other goods and services versus land rent and commuting costs, subject to a budget constraint. Developers, on the other hand, optimize their profit by trading of returns from housing development density versus associated development costs, subject to households' willingness to pay for housing.

Households are defined by their preferences for a certain set of goods and services. At each location $i$, all households are assumed to have identical preferences over the size of their residential space $S_{i}$, the level of environmental amenity value $e_{i}$, and the numerary good $Z_{i}$ representing all non-housing goods and services. While noting that households face a given rental price (price-taker), the household can select the faced rental price and obtained environmental amenity value by choosing the residential location $i$. The household now maximizes utility $U_{i}$ at location $i$ subject to the budget constraint, such that

$$
\underset{S_{i}, Z_{i}}{\operatorname{Max}_{i}} U_{i}\left(S_{i}, Z_{i}\right)=S_{i}^{\mu} Z_{i}^{(1-\mu)} e_{i}^{v}
$$

subject to

$$
y=p_{i}^{h} S_{i}+Z_{i}+p_{x} x_{i}
$$

where $\mu$ and $v$ represent the household's preference for residential space and environmental amenities, respectively, $p_{i}^{h}$ is the rental price for a unit of housing at location $i, y$ is household income, $p_{x}$ the commuting cost per km per year, and where $x_{i}$ is the distance from location $i$ to the Central Business District (CBD). Substitution of the necessary conditions back into eqn (10) yields the household's bid-rent price for housing $p_{i}^{h^{*}}$ at location $i$, which is given by 


$$
p_{i}^{h^{*}}=\left(\frac{\mu^{\mu}(1-\mu)^{(1-\mu)} e_{i}^{v}\left(y-p_{x} x_{i}\right)}{u}\right)^{\frac{1}{\mu}}
$$

where $u$ denotes a given utility level $U$. Eqn (12) gives the household's maximum willingness to pay for housing at location $i$, and represents the demand side of the housing market . For detailed derivation, please refer to [21].

On the supply side, the developer aims to maximize profit $\pi_{i}$ at location $i$, which is given by the development density $D_{i}$ times the rental price per unit of housing $p_{i}^{h}$ net of incurred development costs, and is given by

$$
\underset{D_{i}}{\operatorname{Max}_{i}} \pi_{i}\left(D_{i}\right)=p_{i}^{h} D_{i}-\left(l_{i}+c_{0}+D_{i}^{\eta}\right)
$$

where $\left(l_{i}+c_{0}+D_{i}{ }^{\eta}\right)$ reflects development costs, comprising the opportunity cost of land $l_{i}$ and construction costs $c_{0}+D_{i}{ }^{\eta}$, while noting that $\eta>1$. Substitution of the necessary condition for optimality back into eqn (13) yields the developers bidprice for land $r_{i}{ }^{* *}$ at location $i$, which is given by

$$
r_{i}^{* *}=\left(m p_{i}^{h^{* *}}\right) \frac{\eta}{\eta-1}-c_{0}
$$

with $m=\left[(\eta-1)^{(\eta-1) / \eta}\right] / \eta$. The term $p_{i}^{h^{* *}}$ in eqn (14) is the minimum rental price for housing the developer is willing to accept at location $i$, and represents the supply side of the housing market [21].

In equilibrium, where supply for housing equals demand for housing and thus $p_{i}^{h^{*}}=p_{i}^{h^{* *}}$, the land rent price $r_{i}$ at location $i$ can now be derived using eqn (12) and eqn (14), and is given by

$$
r_{i}=\left(\frac{k e_{i}^{v}\left(y-p_{x} x_{i}\right)}{u}\right)^{\frac{\eta}{\mu(\eta-1)}}-c_{0}
$$

with $k=(\mu m)^{\mu}(1-\mu)^{(1-\mu)}$. The corresponding optimal household density $n_{i}$ at location $i$ is now given by

$$
n_{i}=\frac{D_{i}}{S_{i}}
$$

with $S_{i}=\frac{\mu\left(y-p_{x} x_{i}\right)}{p_{i}^{h^{*}}} \quad$ (necessary condition for optimality $U_{i}$ ) $D_{i}=(\eta-1)^{-\frac{1}{\eta}}\left(r_{i}+c_{0}\right)^{\frac{1}{\eta}}$ (necessary condition for optimality $\pi_{i}$ ) and where $p_{i}^{h^{*}}$ and $r_{i}$ are given in eqn (12) and eqn (15), respectively [21]. 


\subsubsection{Terrestrial benefits for population scenarios in Douglas Shire}

As we're interested in land use patterns and corresponding terrestrial benefits for specific catchment population scenarios, we develop a numerical application of the above described classic urban economic model with environmental amenities for the Douglas Shire catchment, using GAMS 21.3 [3].

The objective function of the numerical model becomes to maximize, for a given catchment population $Q_{t}$, terrestrial benefits $B_{t e r}$ from agricultural land uses $L_{i}^{a g r}$ and residential land uses $L_{i}^{\text {res }}$ over all locations $i$ net of development costs $\left(l_{i}+c_{0}+D_{i}{ }^{\eta}\right)$, so that

$$
\underset{L_{i}}{\operatorname{Max}} B_{\text {ter }}\left(L_{i}\right)=\sum_{i}\left(l_{i} L_{i}^{\text {agr }}+\left(r_{i}-l_{i}-c_{0}-D_{i}^{\eta}\right) L_{i}^{\text {res }}\right)
$$

subject to

$$
Q_{t}=\sum_{i} n_{i} \quad \text { and } \quad L_{i}^{a g r}+L_{i}^{r e s}=a_{i}
$$

where $l_{i}$ is the opportunity cost of land, $r_{i}$ is the land rent price, and $a_{i}$ is the area of location $i$. Note that land use conversion can only taken place between agricultural and terrestrial land uses - all other land uses are fixed.

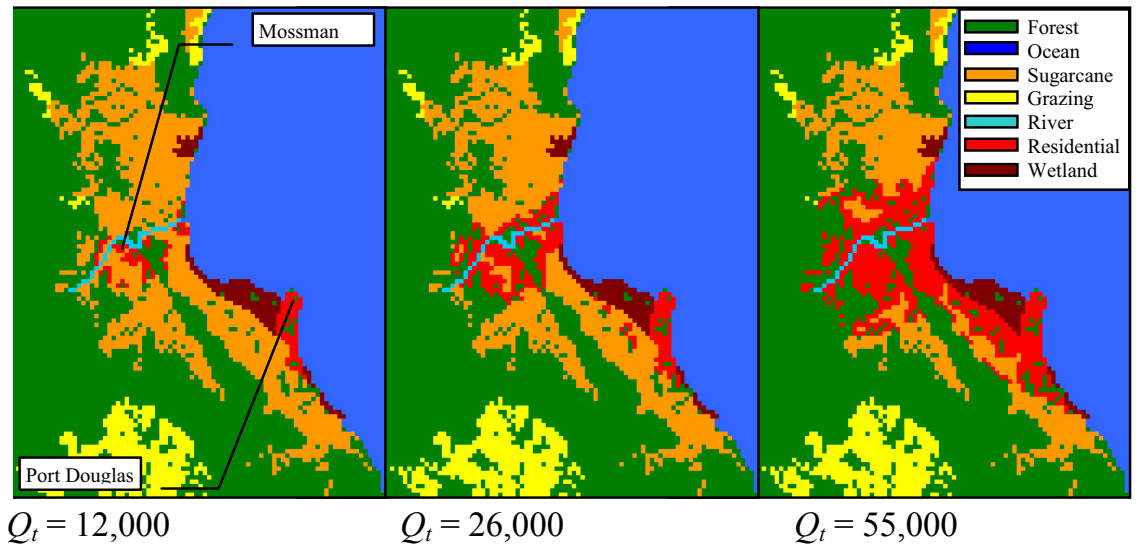

Figure 1: Terrestrial benefit maximizing land use patterns in Douglas Shire for three catchment population scenarios $Q_{t}$.

The numerical application is based on a population comprising two income groups $(y=40,000 \mathrm{~A} \$ / \mathrm{yr}$ for income group 1 and $y=60,000 \mathrm{~A} \$ / \mathrm{yr}$ for income group 2), both income groups share the same utility function $(\mu=0.5$ and $v=$ 0.08 ), income group 2 is $25 \%$ larger than income group 1 (to account for nonresidential property owners), a given utility level $(u=2,702$ for income group 1 and $u=4,053$ for income group 2), annual commuting costs $\left(p_{x}=720 \mathrm{~A} \$ / \mathrm{km}\right)$, opportunity cost of agricultural land $\left(l_{i}=1,800 \mathrm{~A} \$ / \mathrm{yr}\right.$ for sugarcane and $l_{i}=600$ $\mathrm{A} \$ / \mathrm{yr}$ for grazing), development costs $\left(c_{0}=0\right.$ and $\left.\eta=1.385\right)$, two CBDs (Mossman and Port Douglas), two environmental amenities (forest and ocean, 
with equal amenity value $e=10$ ), amenity values are decreasing with distance from the amenity source, and a 185 by 106 grid layer of $250 \mathrm{~m}$ by $250 \mathrm{~m}$ grid cells.

For the current situation, where catchment population $Q_{t}=12,000$, terrestrial benefits from agricultural and residential land uses $B_{t e r}\left(Q_{t}\right)$ equal almost $\mathrm{A} \$ 28$ million per year. As a comparison, terrestrial benefits from agricultural land uses in 2002 equaled about $\mathrm{A} \$ 10$ million [17]. The relationship between population growth, terrestrial benefit maximizing land use development patterns and terrestrial benefits, is now determined for nine catchment population scenarios (ranging from $Q_{t}=12,000$ to $Q_{t}=92,000$ ). In turn, output from these model simulations is used as input for regression analysis. Terrestrial benefits from agricultural and residential land uses $B_{t e r}\left(Q_{t}\right)$ is given by the second order polynomial (in million A\$ per year)

$$
B_{\text {ter }}\left(Q_{t}\right)=\underset{(417.7)}{26.28+1.22 * 10^{-4}} Q_{t}-4.24 * 10^{-10} Q_{t}^{2}
$$

where $Q_{t}$ is catchment population, the $t$-values are provided in parenthesis and the adjusted $R^{2}$ equals 0.99 .

\subsection{Nitrogen water pollution from terrestrial land uses in Douglas Shire}

Nitrogen water pollution from Wet Tropics GBR catchments is considered the most important factor determining GBR health and associated economic values, as it can promote the growth of algae that restrict growth and reproduction of coral [9]. The rate of nitrogen water pollution from terrestrial land uses $g\left(Q_{t}\right)$ is taken to be increasing in the catchment population, while recognizing water pollution from non-residential land uses and acknowledging increasing marginal rates of water pollution from population growth (see eqn (8)).

Given that water pollutant delivery is highly land use location specific, we use the SedNet/ANNEX water quality module of the Landscapes Toolkit [14], to determine nitrogen water pollution for specific land use patterns. SedNet/ANNEX (Sediment River Network model/Annual Network Nutrient Export) estimates the net contribution of a specific land use pattern to mean annual supply, deposition and downstream delivery of nutrients through the construction of nutrient budgets for river networks [1, 7, 22].

For the current situation, where catchment population $Q_{t}=12,000$, the rate of nitrogen water pollution from terrestrial land uses $g\left(Q_{t}\right)$ equals about 480 tons of nitrogen per year, in line with [2] and using land use specific nitrogen run-off data from [2]. The effect of population growth on water pollution is now determined through calculation of nitrogen water pollutant delivery for each of the catchment population scenarios' land use patterns, as generated by the classic urban economic model with environmental amenities (see Section 3.1.2). In turn, output from these SedNet/ANNEX model simulations is used as input for regression analysis. Nitrogen water pollution from terrestrial land uses $g\left(Q_{t}\right)$ is given by the second order polynomial (in tons of nitrogen per year) 


$$
g\left(Q_{t}\right)=241.58+0.02 Q_{t}+9.84 * 10^{-8} Q_{t}^{2}
$$

where $Q_{t}$ is catchment population, the $t$-values are provided in parenthesis and the adjusted $R^{2}$ equals 0.99 .

\subsection{Marine benefits from economic values of the GBR in Douglas Shire}

Marine benefits $B_{\operatorname{mar}}\left(P_{t}\right)$ from use and non-use values of the GBR are, in line with $[5,10,13,15,19]$, taken to be linearly decreasing in the level of marine water pollution (see eqn (5)). While information on current economic use and non-use values of the GBR is widely available, information on the relationship between nitrogen water pollution and marine economic values is poor.

Current use values of the GBR include marine tourism, commercial fishery and recreational fishery benefits, and amount to just over $\mathrm{A} \$ 18$ million per year in 2002 [13]. Current non-use values of the GBR, based on reef visitors' willingness to pay (WTP) to prevent the GBR from degrading, amount to almost $\mathrm{A} \$ 4$ million per year in 2002 [13].

Although the effect of nitrogen water pollution on reef health is widely acknowledged [2,9], the quantitative relationship between nitrogen water pollution and indicators of reef health is currently unavailable and, thus, so is the relationship between nitrogen water pollution and marine based economic values [13]. As a consequence, we are unable to determine the marginal costs of nitrogen water pollution $\beta_{2}$, and we will therefore perform a sensitivity analysis with respect $\beta_{2}$ in the next Section.

\section{Welfare maximizing catchment population in Douglas Shire}

Based on the parameter estimates for $B_{t e r}\left(Q_{t}\right), g\left(Q_{t}\right)$ and $B_{\text {mar }}\left(P_{t}\right)$, as derived in Section 3, we use the deterministic model of urbanization in a linked terrestrial and marine ecosystem, as developed in Section 2, to determine welfare maximizing catchment populations $Q^{*}$ in Douglas Shire for a range of time discount rates $r$ and marginal nitrogen water pollution costs $\beta_{2}$ (see Table 1).

Given a time discount rate of $5 \%$ per year while ignoring residential development induced downstream consequences from nitrogen water pollution $\left(\beta_{2}=0\right)$, we see that the welfare maximizing catchment population would be over ten times larger than the current catchment population of 12,000 in Douglas Shire. This essentially means an almost complete conversion of agricultural land uses into residential land uses, indicating that for most locations the returns from residential land uses outweigh those from agricultural land uses.

The sensitivity analysis shows that the welfare maximizing population $Q^{*}$ is linearly increasing in the discount rate $r$ as future losses in marine benefits, resulting from nitrogen water pollution associated with (population induced) residential development, receive less weight as compared to the immediate terrestrial benefits from these residential developments. 
Table 1: Welfare maximizing catchment populations $\left(Q^{*}\right)$ in Douglas Shire for discount rates $(r)$ and marginal nitrogen water pollution costs $\left(\beta_{2}\right)$.

\begin{tabular}{|c|c|c|c|c|c|c|}
\hline & \multicolumn{6}{|c|}{ Marginal nitrogen water pollution costs $(\mathrm{A} \$ / \mathrm{t})$} \\
\hline$R$ & $\beta_{2}=0$ & $\begin{array}{c}\beta_{2}= \\
-1000\end{array}$ & $\begin{array}{c}\beta_{2}= \\
-2000\end{array}$ & $\begin{array}{c}\beta_{2}= \\
-3000\end{array}$ & $\begin{array}{c}\beta_{2}= \\
-4000\end{array}$ & $\begin{array}{c}\beta_{2}= \\
-5000\end{array}$ \\
\hline $0.0 \%$ & 143,454 & 97,733 & 66,505 & 43,822 & 26,599 & 13,075 \\
\hline $2.5 \%$ & 143,454 & 98,642 & 67,797 & 45,269 & 28,094 & 14,567 \\
\hline $5.0 \%$ & 143,454 & 99,516 & 69,046 & 46,675 & 29,552 & 16,025 \\
\hline $7.5 \%$ & 143,454 & 100,356 & 70,255 & 48,041 & 30,974 & 17,450 \\
\hline $10.0 \%$ & 143,454 & 101,165 & 71,425 & 49,369 & 32,360 & 18,844 \\
\hline
\end{tabular}

Note: We take $\rho=-1$, indicating that marine water pollution has a one time impact on the GBR and associated marine economic values.

In addition, it is shown that the welfare maximizing population $Q^{*}$ is decreasing in marginal water pollution costs $\beta_{2}$. Optimality requires that we increase catchment population up to the level where marginal terrestrial benefits from (population induced) residential development equal the discounted sum of marginal marine costs from water pollution associated with this residential development. Consequently, larger marginal marine costs from water pollution need to be matched by larger marginal terrestrial benefits from (population induced) residential development - which is achieved by limiting catchment population growth and associated residential development to locations that are characterized by higher land rents.

As already mentioned in Section 3.3, the costs from downstream nitrogen water pollution are currently not known. However, if these costs would be A $\$ 5,000$ per ton of nitrogen, than the potential welfare gains from population growth and associated residential development in Douglas Shire would be limited. Given a time discount rate of $5 \%$ per year, the welfare maximizing catchment population would be only $25 \%$ larger than the current catchment population in Douglas Shire.

\section{Conclusions}

Welfare gains from population growth and associated urbanization patterns in linked terrestrial and marine ecosystems have, to the knowledge of the authors, not been explored to date. While various studies relate returns from agricultural land uses to marine economic values $[5,10,13,15,19]$, none have linked returns from agricultural as well as residential land uses to marine economic values. In this paper we developed a deterministic optimal control approach in which we compare terrestrial benefits from population induced residential development patterns and, subsequent, marine costs from water pollution associated with these residential development patterns, to explore potential welfare gains that can be obtained from population growth. 
Results indicate that the welfare maximizing population size depends to a large extent on whether downstream costs from water pollution, resulting from residential developments, are taken into account. If we ignore the downstream costs from nitrogen water pollution, the welfare maximizing catchment population in Douglas Shire would be over ten times larger than the current catchment population. If, however, these downstream costs from nitrogen water pollution amount to, say, $\mathrm{A} \$ 5,000$ per ton of nitrogen, the welfare maximizing catchment population in Douglas Shire would be only $25 \%$ larger than the current catchment population.

Some caveats remain. First, negative and positive feedbacks from residential development on environmental and urban amenities, are not taken into account. The net effect of these two feedbacks on terrestrial benefits from agricultural and residential land uses is unsure, as environmental amenities are likely to degrade while urban amenities may improve with residential development $[4,6]$. Second, size and composition of population growth should be considered an endogenous rather than an exogenous variable. As shown in [20], population influx may accelerate or decelerate depending on residential development patterns and associated consequences for environmental and urban amenities. Finally, the developed deterministic approach is likely to result in biased outcomes as uncertainty in marine benefits from GBR conservation are not taken into account. Accounting for this uncertainty would lead to lower welfare maximizing populations, provided that downstream effects and associated costs from population growth induced water pollution are taken into account [8].

\section{References}

[1] Bartley, R., Henderson, A., Baker, G., Bormans, M. \& Wilkinson, S., Patterns of Erosion and Sediment Nutrient Transport in the Douglas Shire Catchments (Daintree, Saltwater, Mossman and Mowbray), CSIRO Land and Water, Atherton, 2004.

[2] Brodie, J., McKergow, L.A., Prosser, I.P., Furnas, M., Hughes, A.O. \& Hunter, H., Sources of Sediment and Nutrient Exports to the Great Barrier Reef World Heritage Area, Australian Centre for Tropical Freshwater Research, Townsville, 2003.

[3] Brooke, A., Kendrick, D., Meerhaus, A. \& Raman, R., GAMS Release 2.5: A User's Guide, GAMS Development Corporation, Washington, 1998.

[4] Brueckner, J.K., Thisse, J.F \& Zenou, Y., Why is Paris rich and downtown Detroit poor? An amenity-based theory, European Economic Review, 43, pp. 91-107, 1999.

[5] Cesar, H.S.J., van Breukingen, P., Pintz, S. \& Dierking, J., Economic Valuation of the Coral Reefs of Hawaii, Hawaii Coral Reef Initiative Research Program, Hawaii, 2002.

[6] Dendrinos, D.S., Land development and amenities: a predator-prey interactions, The Annals of Regional Science, 34, pp. 279-292, 2000. 
[7] DeRose, R.C., Prosser, I.P., Wilkinson, L.J., Hughes, A.O. \& Young, W.J., Regional Patterns of Erosion and Sediment and Nutrient Transport in the Mary River Catchment, Queensland, CSIRO Land and Water, Canberra, 2003.

[8] Dixit, A.K. \& Pindyck, R.S., Investment under Uncertainty, Princeton University Press, Princeton, 1994.

[9] Furnas, M., Catchments and Corals: Terrestrial Runoff to the Great Barrier Reef, Australian Institute of Marine Science, Townsville, 2003.

[10] Gustavson, K. \& Huber, R.M., Ecological economic decision support modelling for the integrated coastal zone management of coral reefs, Collected Essays on the Economics of Coral Reefs, ed. H.S.J. Cesar, CORDIO, Department for Biology and Environmental Science, Kalmar University, Kalmar, pp. 183-202, 2000.

[11] Mills, E.S. \& Hamilton, B., Urban Economics $-5^{\text {th }}$ Edition, HarperCollins, 1994.

[12] O'Sullivan, A., Urban Economics - 4th Edition, McGraw Hill, New York, 2000.

[13] Roebeling, P.C., Efficiency in Great Barrier Reef water pollution control: a case study for the Douglas Shire, Natural Resource Modeling, 19(4), pp. 539-556, 2006.

[14] Roebeling, P.C., Bohnet, I., Smith, M., Westcott, D., Williams, K.J., Kroon, F., Hartcher, M., Hodgen, M. \& Vleeshouwer, J., Landscapes Toolkit for triple-bottom-line assessment of land use scenarios in Great Barrier Reef catchments, MODSIM 2005 International Congress on Modeling and Simulation, eds. A. Zerger \& R. Argent, Modeling and Simulation Society of Australia and New Zealand, pp. 711-717, 2005.

[15] Ruitenbeek, J., Ridgley, M., Dollar, S. \& Huber, R., Optimization of Economic Policies and Investment Projects Using a Fuzzy Logic Based Cost-Effectiveness Model of Coral Reef Quality: Empirical Results for Montego Bay, Jamaica, World Bank, Washington, 1999.

[16] RWQPP (Reef Water Quality Protection Plan), Reef Water Quality Protection Plan for Catchments Adjacent to the Great Barrier Reef World Heritage Area, Queensland Government, Department of Premier and Cabinet, Brisbane, 2003.

[17] Smith, D.M., Roebeling, P.C., Webster, A.J., Kragt, M., Bohnet, I. \& Zull, A., Assessment of the Socio-Economic Impacts of Management Options for Improving Water Quality in the Douglas Shire, CSIRO-Sustainable Ecosystems, Townsville, 2005.

[18] Vitousek, P.M., Beyond global warming: ecology and global change. Ecology, 75(7), pp. 1861-1876, 1994.

[19] Wielgus, J., Chadwick-Furman, N.E., Dubinsky, Z., Shechter, M. \& Zeitouni, N., Dose-response modelling of recreationally important coralreef attributes: a review and potential application to the economic valuation of damage, Coral Reefs, 21, pp. 253-259, 2002. 
[20] Wu, J., Environmental amenities, urban sprawl, and community characteristics, Journal of Environmental Economics and Management, 52, 527-547, 2006.

[21] Wu, J. \& Plantinga, J., The influence of public open space on urban spatial structure. Journal of Environmental Economics and Management, 46, pp. 288-309, 2003.

[22] Young, W. J., Rustomji, P., Hughes, A.O. \& Wilkins, D., Regionalisations of Flow Variables used in Modelling Riverine Material Transport in the National Land and Water Resources Audit, CSIRO Land and Water, Canberra, 2001.

[23] Zipperer, W.C., Wu, J., Pouyat, R.V. \& Pickett, S.T.A., The application of ecological principles to urban and urbanizing landscapes, Ecological Applications, 10(3), pp. 685-688, 2000. 